\title{
Effect of the Fv-1 Locus on the Titration of Murine Leukemia Viruses
}

\author{
PAUL JOLICOEUR AND DAVID BALTIMORE* \\ Department of Biology and Center for Cancer Research, Massachusetts Institute of Technology, Cambridge, \\ Massachusetts 02139
}

Received for publication 31 July 1975

\begin{abstract}
Titration of $\mathrm{N}$ - and B-tropic murine leukemia viruses on sensitive and resistant cell lines has been studied by direct XC plaque assay and infective center assay. The titration of a cloned B-tropic virus by infective center assay on BALB/3T3 (Fv-1 $1 / b)$ and NIH/3T3 (Fv-1 ${ }^{\mathrm{n} / n}$ ) cells gave one-hit patterns, with 100fold less infected NIH/3T3 cells than BALB/3T3 cells. The titration of B-tropic virus on DBA/2 cells $\left(\mathrm{Fv}-1^{\mathrm{n} / \mathrm{n}}\right)$ was also one-hit. The titration of a cloned N-tropic virus on NIH/3T3 and BALB/3T3 cells gave a one-hit curve, and there were about 100-fold less infected BALB/3T3 cells than NIH/3T3 cells. Comparable results were obtained by titrating the cloned $\mathrm{N}$-tropic virus on congenic SIM ( $\mathrm{Fv}$ $\left.1^{n / n}\right)$ and SIM.R $\left(F v-1^{b / b}\right)$ cells or the Gross N-tropic virus on BALB/3T3 cells. Therefore, our data indicate that the multiple-hit phenomenon described previously may not be an essential part of the Fv-1 gene restriction.
\end{abstract}

The naturally occurring murine leukemia viruses can be classified according to their host range. They are called N- or B-tropic viruses if they grow preferentially on NIH or BALB cells, respectively. The viruses that grow as well on both cells are called NB-tropic (6). This growth property is regulated by a single genetic locus, Fv-1 (11, 13; reviewed in reference 10). Cells of all inbred strains of mice can be classified by their sensitivity to MuLV. N-type (Fv-1 $\left.{ }^{n / n}\right)$ cells will sustain the growth of $\mathrm{N}$-tropic viruses preferentially, whereas B-type $\left(\mathrm{Fv}-1^{\mathrm{b} / \mathrm{b}}\right)$ cells will allow B-tropic viruses to grow better (11). Since resistance is dominant (11), the Fv- $1^{\mathrm{n} / \mathrm{b}}$ heterozygote cells are resistant to both $\mathrm{N}$ - and B-tropic viruses.

In their initial studies of viral host range, Hartley et al. (quoted in reference 10) reported that the viral titration on resistant cells showed a two-hit pattern and that the resistance can be overcome with high multiplicity of infection (MOI). Two recent studies $(3,12)$ have amplified this observation. These results implied that experiments on Fv-1 requiring a high MOI would not be interpretable because the restriction under study would have disappeared.

The action of the Fv-1 gene occurs after penetration of the cells by the restricted viruses (7, 9). To study the intracellular restriction, we have produced clones of $\mathrm{N}$ - and $\mathrm{B}$-tropic viruses derived from BALB/c mice. Attempts to assay these viruses in restrictive cells by direct XC plaque assay gave, to our surprise, a reproducible one-hit pattern. We present here an analy- sis of such titrations. We find that the titration of a cloned virus in resistant cells is one-hit and that the resistance is not overcome by a high MOI. Schuh, Blackstein, and Axelrad (personal communication) have also obtained evidence for one-hit titration of murine leukemia viruses across the Fv-1 barrier.

During the course of this study we became aware of the detailed study of Pincus et al. (12) suggesting a two-hit response of infection across the Fv-1 barrier. We have attempted to use their methods where possible but have still not found a two-hit response.

\section{MATERIALS AND METHODS}

Cells. BALB/3T3 clone A31 (1) and NIH/3T3 (8) were obtained from Robert Pollack. The congenic cell lines SIM and SIM.R (17) were obtained from Arthur A. Axelrad. DBA/2 cells were obtained at the eighth passage from Walter A. Nelson-Rees. This fibroblastic line was derived from the spleen of a normal DBA/2 mouse. Experiments were done with cells between passages 10 and 20 . Cells were grown in Dulbecco modified Eagle medium with $10 \%$ calf serum (BALB/3T3, NIH/3T3) or $10 \%$ inactivated fetal calf serum (DBA/2, SIM, SIM.R).

Viruses. The Gross virus was provided by Nancy Hopkins. This virus was originally obtained from $\mathbf{T}$. Pincus and was grown on NIH/3T3 cells.

$\mathrm{N}$-tropic virus (WN 1802N, pool 1898) and B-tropic virus (WN 1802B, pool 1948) were obtained from Janet Hartley and Wallace P. Rowe. They were isolated from the spleen of a normal old BALB/c mouse as described (5). The $\mathrm{N}$ - and B-tropic virus stocks were used in this laboratory to infect NIH/3T3 and $3 T 6$ cells, respectively, and the viruses produced 
by these chronically infected cells were cloned. The $\mathrm{N}$ - and B-tropic viruses were cloned by a described procedure (15) on NIH/3T3 and BALB/3T3 cells, respectively. Briefly, cells were infected at very low multiplicity $(0.001)$ and trypsinized $3 \mathrm{~h}$ later, and 100 cells were delivered to each of 96 wells of a Falcon microtest II plate. The medium from each well was assayed for XC plaque-forming ability 7 to 10 days after infection. Positive cultures were picked and established as mass cultures, and those having the highest virus titer were selected for virus production. All our studies have been done with one isolate of $\mathrm{N}$-tropic virus (N-Cl-35) and one isolate of B-tropic virus (B-Cl-11).

Direct plaque assay. Stock viruses were titered on NIH/3T3 cells (N-tropic and Gross viruses) or BALB/3T3 cells (B-tropic virus) in the presence of 8 $\mu \mathrm{g}$ of polybrene per $\mathrm{ml}$ (Aldrich) using the XC plaque assay as described (14). The titer of stocks varied from $0.5 \times 10^{6}$ to $2 \times 10^{6} \mathrm{PFU} / \mathrm{ml}$. For titration studies, the number of plaques counted was converted to percentage of cells infected by dividing the number of plaques by the number of cells at the time of infection $(50,000)$.

Virus infection. For titration studies, the virus suspension was centrifuged at $5,000 \mathrm{rpm}$ for $30 \mathrm{~min}$ as suggested (12), and the upper half of the supernatant was sonicated for $10 \mathrm{~s}$ in a Raytheon sonic oscillator. None of these procedures affected the virus titer significantly (Table 1 ). The virus preparation was diluted in Dulbecco modified Eagle medium without serum and used for infection.

Cells were plated 15 to $20 \mathrm{~h}$ before infection in the presence of $2 \mu \mathrm{g}$ of polybrene per $\mathrm{ml}$ at a concentration of 50,000 cells $/ 60-\mathrm{mm}$ petri dish. When a large number of cells were required for an infective center assay, this cell density was never changed, but more dishes were infected and the cells were pooled.

Cells were infected with $0.2 \mathrm{ml}$ of virus suspension for $1.5 \mathrm{~h}$ at $37 \mathrm{C}$. After infection the cell layer was covered with medium and UV irradiated 4 to 5 days later for a direct XC assay (14), or processed $5 \mathrm{~h}$ later for an infective center assay.

Infective center assay. Five hours after infection, cells were washed twice with phosphatebuffered saline $\left(\mathrm{NaCl}, 8.0 ; \mathrm{KCl}, 0.2 ; \mathrm{KH}_{2} \mathrm{PO}_{4}, 0.2\right.$ $\mathrm{Na}_{2} \mathrm{HPO}_{4}, 1.2 \mathrm{~g} /$ liter), treated for $10 \mathrm{~min}$ with $0.5 \%$ trypsin (Nutritional Biochemicals Co., 1:250) at room temperature, centrifuged away from the trypsin, diluted in medium, and plated at various density on cells sensitive to the virus under study (NIH/3T3 or BALB/3T3). These sensitive cells (30,000 cells/60-mm petri dish) were prepared the day before in the absence of polybrene. Routinely, less than 20,000 cells were seeded on the sensitive cultures. When it was necessary to seed more cells, they were divided among several dishes and the results were pooled. Four days after the cell transfer, cultures were UV irradiated and the XC assay was performed (14).

For each point, aliquots of infected cells were seeded on 100-mm petri dishes, in triplicate, for plating efficiency. From 10 to $\mathbf{1 5}$ days later, plates were fixed and stained, and colonies greater than 3 mm were counted.
The percentage of cells infected was obtained from the number of plaques seen in the XC assay and the number of colonies scored. The MOI was calculated using the titer of the stock virus on permissive cells and the number of cells plated $(50,000)$. Data are plotted as described by Pincus et al. (12).

Freeze-thaw treatment. BALB/3T3 cells were infected with B-tropic virus (MOI $=1$ ), and $4 \mathrm{~h}$ later cells were trypsinized in $0.5 \%$ trypsin and diluted. The cell suspension was divided into two parts. One part was kept at room temperature. The other part was subjected to two cycles of freeze-thaw (dry iceacetone and $37 \mathrm{C}$ ). Both cell suspensions were then plated on BALB/3T3 cells prepared the day before for a standard infective center assay.

\section{RESULTS}

Infection of $\mathrm{Fv}-1^{\mathrm{n} / \mathrm{n}}$ cells with B-tropic virus. Figure 1 shows a titration by infective center assay of B-tropic virus on a sensitive Fv$1^{\mathrm{b} / \mathrm{b}}$ cells line (BALB/3T3) and on a restrictive Fv-1 ${ }^{n / n}$ cell line (NIH/3T3). Both curves were parallel to each other and also to a theoretical one-hit curve. For any MOI, the number of $\mathrm{NIH} / 3 \mathrm{~T} 3$ cells infected was approximately 100 fold lower than the number of infected BALB/3T3 cells. If sensitive and restrictive cells were infected at a higher MOI than 1 , the percentage of positive cells in the infective center assay was not increased. Both curves reached a plateau at less than $100 \%$ of the cells infected. This might indicate that homologous interference by noninfectious particles is limiting the number of PFU that could be absorbed. Alternative explanations are inefficiency of the infective center assay or a delay in viral expression (2). As shown, sensitization of NIH/3T3 cells with either polybrene or DEAE-dextran gave similar results.

Pincus et al. (12) suggested that DBA/2 cells infected with B-tropic virus were the only Fv$1^{n / n}$ cell type that did not show inhibitory effects synergistic with $\mathrm{Fv}-1$ restriction. To determine if the one-hit curve obtained on restrictive NIH/3T3 cells was a more general phenomenon,

TABLE 1. Effect of centrifugation and sonication on virus titer ${ }^{a}$

\begin{tabular}{|c|c|}
\hline Treatment & PFU/ml \\
\hline $\begin{array}{l}\text { None } \ldots \ldots \ldots \ldots \ldots \\
\text { Centrifugation } \ldots \ldots \\
\text { Sonication } \ldots \ldots \ldots\end{array}$ & $\begin{array}{r}5 \times 10^{4} \\
6.5 \times 10^{4} \\
9 \times 10^{4}\end{array}$ \\
\hline
\end{tabular}

${ }^{a}$ B-CL-11 virus suspension was diluted in Dulbecco medium and centrifuged at $5,000 \mathrm{rpm}$ for 30 min, and the upper half of the supernatant was sonicated. Portions were withdrawn before the procedure, after centrifugation, and after sonication for virus titration on BALB/3T3 cells. 


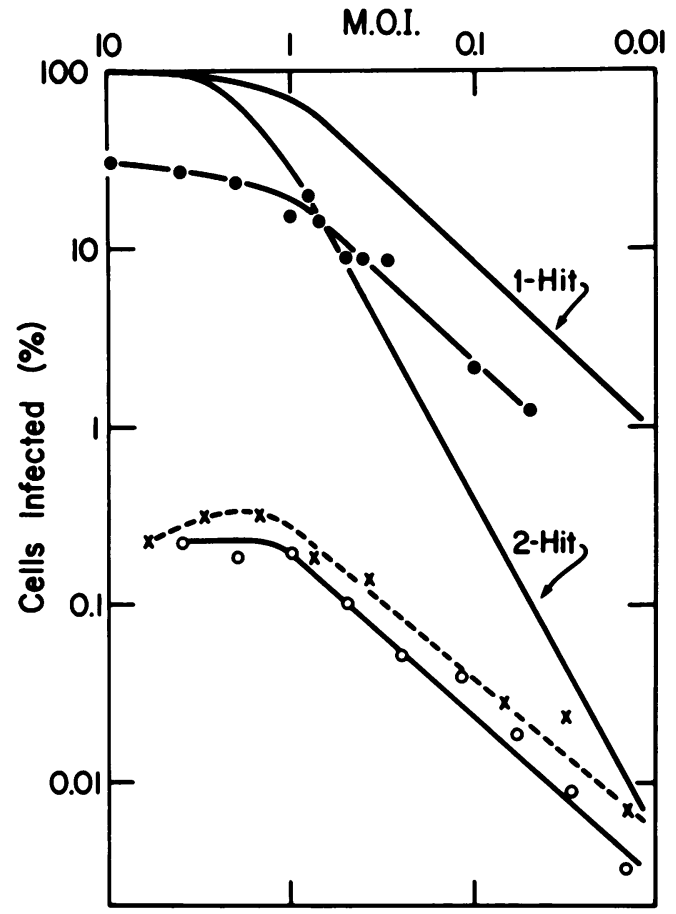

Fig. 1. Titration of B-tropic virus on BALB/3T3 and NIHBT3 cells. Cells were infected with WN $1802 B$ virus (B-Cl-11), and the percentage of infected cells was determined by the infective center assay. Cells were treated for $15 h$ with $2 \mu g$ of polybrene (solid line) per $\mathrm{ml}$ or with DEAE-dextran $(25 \mu \mathrm{g} / \mathrm{ml}$ ) for $1 \mathrm{~h}$ at $37 \mathrm{C}$ (dashed line) before infection. The theoretical Poisson distribution for cells infected with one (1-hit) or two (2-hit) particles is shown. Symbols: (O) BALBBT3 cells; $(\times, O)$ NIHBT3 cells.

B-tropic virus was titered by infective center assay on DBA/2 cells. This titration gave a onehit curve with a plateau at an MOI higher than 1 and a maximum of $1 \%$ infective centers (Fig. 2). For any given MOI, comparing the number of $\mathrm{DBA} / 2$ cells infected with the number of NIH/3T3 cells infected (see Fig. 1), the percentage of infected DBA/2 cells is two to five times higher than the percentage of infected NIH/3T3 cells. These data are consistent with the observation that DBA/2 cells have a lower "refractoriness factor" (12), or, alternatively, that the Fv$1^{n}$ allele has less penetrance on this background.

Infection of $\mathrm{Fv}-1^{\mathrm{b} / \mathrm{b}}$ cells with $\mathrm{N}$-tropic virus. Figure 3 shows the result of titration of the $\mathrm{N}$-tropic virus, $\mathrm{N}-\mathrm{C} 1-35$, by infective center assay and by direct plaque assay on NIH/3T3 and BALB/3T3 cells. Again, both curves were parallel to each other and showed one-hit patterns at an MOI lower than 0.1 . There were about 50- to 70-fold less infected BALB/3T3 cells than in- fected NIH/3T3 cells at any given MOI. The curves reached a plateau at an MOI of 0.1 , a virus-to-cell ratio 10 times lower than was saturating for the B-tropic virus (Fig. 1); the N-C135 virus stock might have contained a 10 -fold higher concentration of interfering particles per infectious virus. The percentages of infected BALB/3T3 cells scored by the direct plaque assay and by the infective center assay were identical.

To determine whether a one-hit pattern would be found for an $\mathrm{N}$-tropic virus infecting a different $\mathrm{Fv}-1^{\mathrm{b} / \mathrm{b}}$ cell line, a cell line derived from SIM.R mice was studied. SIM and SIM.R are congenic lines for Fv-1 (17). The titration of N-C1-35 on SIM and SIM.R cells is shown in Fig. 4. The dose-response curve, measured by the infective center assay on the sensitive SIM cells, is one-hit. The titration of N-C1-35 on SIM.R cells by the infective center assay and the direct XC plaque assay show that the percentage of infected cells observed by the two techniques is drastically different. The direct XC plaque assay scored 10- to 100 -fold less infected cells than the infective center assay. Pincus et al. (12) have observed this phenomenon in many cell types. Both curves are close to, but not exactly, one-hit. The curve obtained by the direct XC plaque assay is slightly steeper than one-hit, and the curve obtained from data of the infective center assay is slightly less than onehit. Neither curve, however, appears to be twohit. There are about 40- to 60 -fold less infected SIM.R cells than infected SIM cells.

The titration of N-tropic virus on Fv-1 ${ }^{\mathrm{b} / \mathrm{b}}$ cells was also studied, using an $\mathrm{N}$-tropic virus origi-

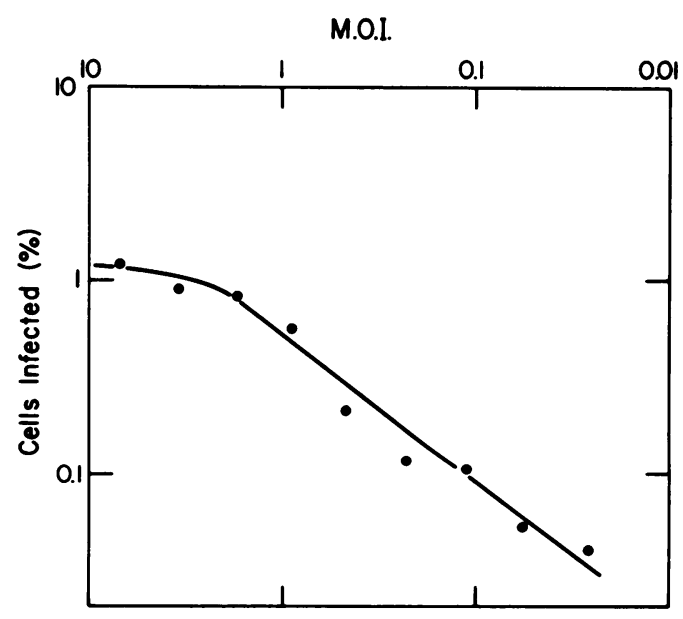

Fig. 2. Titration of $B$-tropic virus on $D B A / 2$ cells. Cells (passage 12) were infected with $B-C l-11$, and the percentage of infected cells was determined by the infective center assay. 


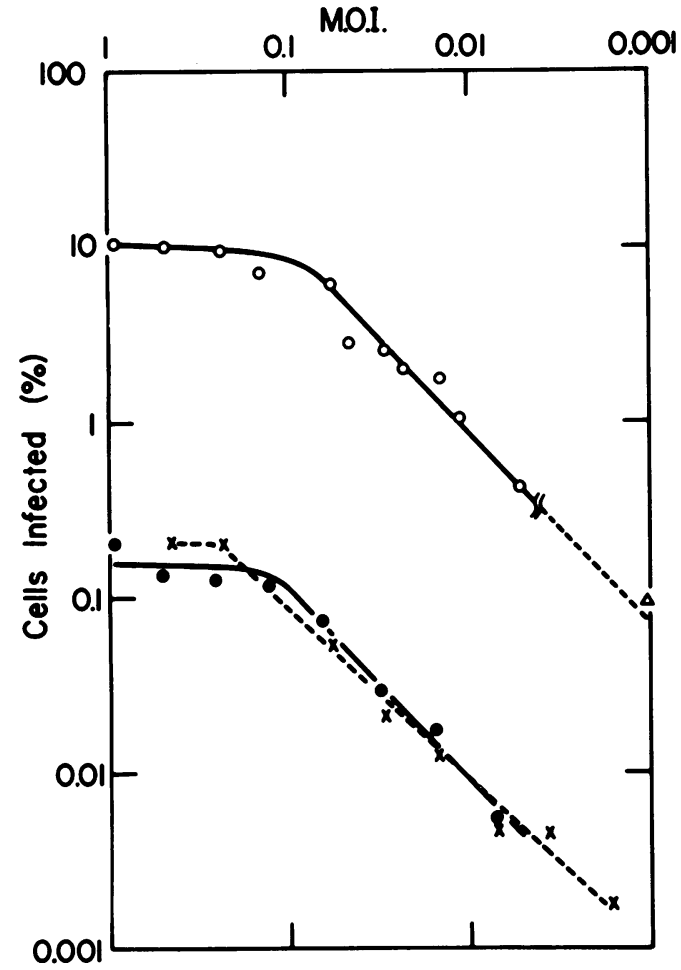

Fig. 3. Titration of N-tropic virus on NIH/3T3 and BALB/3T3 cells. Cells were infected with $N$ tropic virus $(\mathrm{N}-\mathrm{Cl}-35)$, and the percentage of infected cells was determined by infective center assay (solid line) or by direct plaque assay (dashed line). Symbols: $(\triangle$, , ) NIHBT3; $(\times$, O) BALBBT3.

nating from a different inbred strain of mice, the Gross virus from AKR mice. By the XC plaque assay, the titration of this virus on BALB/3T3 cells was one-hit (Fig. 5).

One-hit titration and residual viruses. In the infective center assay, the restrictive cells are infected and then transferred to a culture sensitive to the virus under study. In this assay, any free infectious residual viral particle transferred with the cells would grow in its sensitive host and invalidate the assay. To test whether the infectious centers represent true eclipsed virus-cell complexes, we determined whether the infected cells themselves were responsible for plaque formation. Freezing and thawing an infected cell suspension caused loss of all infective centers, whereas the titer of a virus suspension subjected to the same treatment was not changed (Table 2). These data show that the XC plaques scored in the infective center assay were not due to residual infectious viral particles.

\section{DISCUSSION}

Our data show that the titration of N- or Btropic viruses in Fv-1-resistant cell lines gave one-hit curves and that the Fv-1 gene restriction cannot be overcome by a high MOI. We have observed this pattern with three different viruses, two of which had been cloned, and on five different established cell lines. It is likely to be a general phenomenon, although the possibility remains that different titration curves can be obtained with different viruses, especially if they are not cloned.

These results are in contradiction with the observations of others, which have indicated that the dose-response of $\mathrm{N}$ - or B-tropic viruses on resistant cells give a two-hit pattern $(3,12$, $16,18)$. Pincus et al. (12) have further suggested that the Fv-1 gene restriction can be overcome

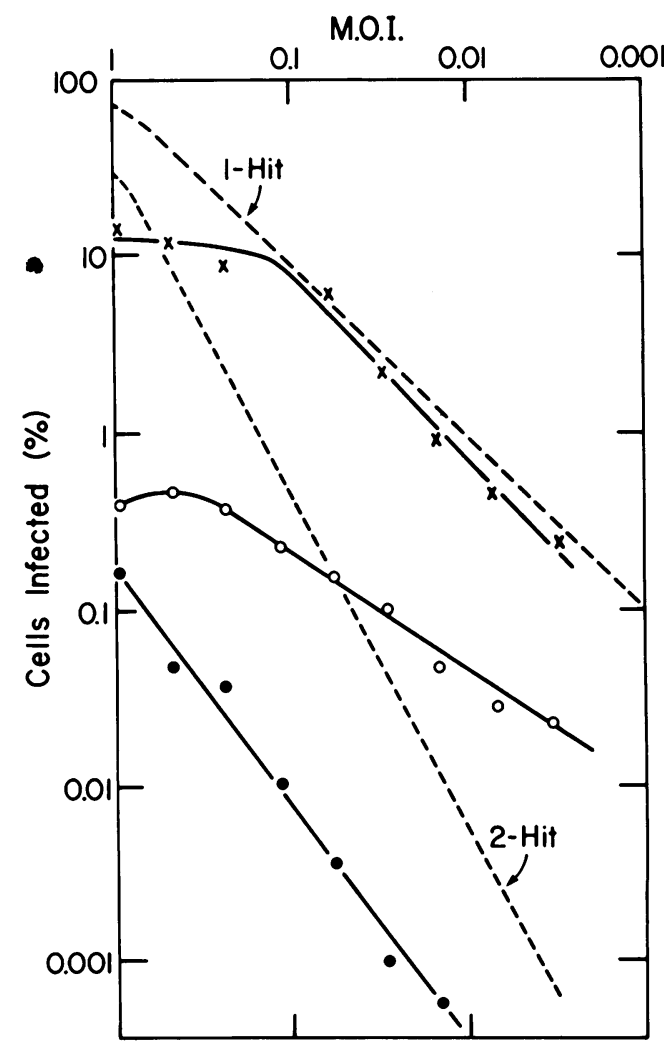

Fig. 4. Titration of N-tropic virus on SIM and SIM.R cells. Cells were infected with $\mathrm{N}-\mathrm{Cl}-35$ virus, and the percentage of infected cells was determined by infective center assay $(O, X)$ and by direct XC plaque assay (O). The Poisson distribution for one (1-hit) and two (2-hit) particles is shown on the graph (dashed line). Symbols: (O, O) SIM.R cells; (X) (SIM) cells. 


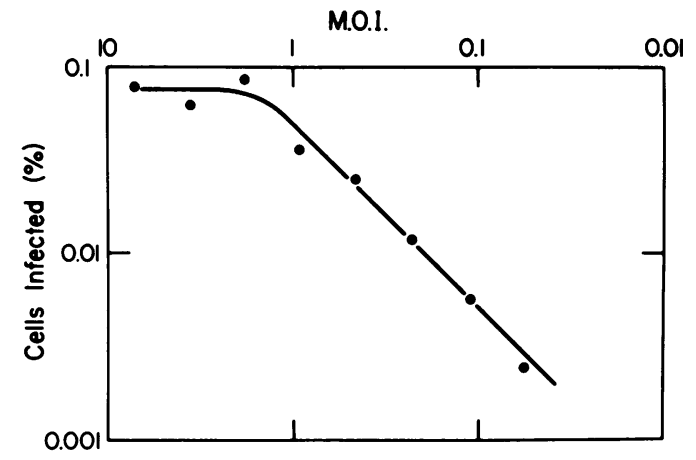

Fig. 5. Titration of $N$-tropic Gross virus on $B A L B / 3 T 3$ cells. Cells were infected with Gross virus, and the percentage of infected cells was determined by the direct XC plaque assay.

TABLE 2. XC plaque formation of an infected cell suspension and $a$ virus suspension after freezing and thawing

\begin{tabular}{llcr}
\hline Procedure & $\begin{array}{c}\text { Infected cell } \\
\text { suspension }^{a} \\
\text { (plaques) }^{\text {Calonies }}\end{array}$ & $\begin{array}{c}\text { Colo } \\
(\%)\end{array}$ & $\begin{array}{c}\text { Virus sus- } \\
\text { pension } \\
(\text { PFU/ml) }\end{array}$ \\
\hline $\begin{array}{l}\text { Control } \\
\begin{array}{c}\text { Freezing and } \\
\text { thawing }\end{array}\end{array}$ & 99,94 & 100.0 & $3 \times 10^{4}$ \\
\hline
\end{tabular}

${ }^{a}$ BALB/3T3 cells were infected with B-tropic virus, and $4 \mathrm{~h}$ later cells were trypsinized in $0.5 \%$ trypsin, diluted, and subjected to freezing and thawing.

by a high MOI, although in the many N-type cells they have studied (C57BR, C57L, [C57BR $\times$ C57L] $\left.F_{1}, \mathrm{C} 3 \mathrm{H}, \mathrm{NIH}\right)$ the restriction was not overcome by a high virus input. Since these titration curves showed a lower percentage of infected cells than expected from the theoretical two-hit Poisson distribution, they have concluded that a new form of restriction ("refractoriness factor"), distinct from the Fv-1 restriction, could be operating. But if the viral titration on resistant cells is one-hit, as we have shown, this phenomenon might well be part of the Fv-1 gene restriction. Another indication that the two-hit phenomenon might not be an essential part of the Fv-1 function comes from the interesting observation of Declève et al. (3) that titration of the B-tropic radiation leukemia virus on $\left(\mathrm{NIH} \times \mathrm{C}\right.$ 7BL) $\mathrm{F}_{1}$ and $(\mathrm{C} 57 \mathrm{BL} \times$ NIH)F $F_{1}$ hybrid cells gave one-hit patterns.

At the moment, we cannot offer any explanation for the contradiction between our results and those of others. It appears that under some experimental conditions the "hitness" factor is operative whereas under other (ill-defined) conditions the "hitness" factor is not evident, de- spite the fact that the Fv-1-mediated restriction is still present. We have tried to rule out the most obvious reasons that could lead to different data. We do not feel these conflicting results can be explained by (i) the assay itself, because we have obtained similar data with two different assays (direct XC plaque and infective center assay); (ii) the method of infection, because we have obtained identical data when cells were presensitized with polybrene (2 $\mu \mathrm{g} / \mathrm{ml}$ ) or DEAE-dextran, or infected in the presence of polybrene $(8 \mu \mathrm{g} / \mathrm{ml})$; or (iii) virus clumps, because, to avoid this complication, we have taken care to eliminate possible clumps in our viral suspensions by centrifuging them and dispersing them by sonication just before infection. The one-hit pattern on resistant cells as measured by infective center assay cannot be due to residual virus, because the infective centers are sensitive to freezing and thawing (Table 2). It is unlikely that the cell lines we have worked with have been mixed or have lost their Fv-1 character, as reported for $\mathrm{S}^{+} \mathrm{L}^{-}$cells (4), because these lines not only show a one-hit titration pattern but have maintained their Fv1 gene restriction as well. This last property operationally defines a Fv-1-type cell. Moreover, identical results have been obtained with freshly thawed cells over a period of 10 months, and with cells obtained from other laboratories.

Observations similar to ours have also been made in other laboratories. Ware and Axelrad first reported a two-hit titration of $\mathrm{N}$-tropic Friend virus on SIM.R cells (17). But, after a more detailed study, the pattern seen has been reinterpreted as one-hit (Schuh et al., personal communication). Eckner (personal communication) has also observed the one-hit pattern in Fv-1 restrictive cells (BALB/3T3) using the Friend strain of murine leukemia virus. Pincus et al. (12) have also noticed, in many experiments, one-hit titration at high viral dilutions.

From the present work it appears that Fv-1mediated restriction is a simple event in which a cellular gene product inactivates a large fraction of viruses sensitive to the action of the restriction factor. This event is thought to occur after adsorption and penetration because pseudotypes of $\mathrm{N}$ - and $\mathrm{B}$-tropic virus coating the vesicular stomatitis virus genome are not sensitive to the action of the Fv-1 gene product $(7,9)$. A reasonable model is that the nucleic acid (RNA or DNA copy) of the virus is sensitive to a restriction enzyme or to the action of a repressor gene.

The practical implications of our results is the ability to design experiments requiring a high MOI to study the Fv-1 gene functions at a 
molecular level. We are currently involved in such experiments to test models of Fv-1 action.

\section{ACKNOWLEDGMENTS}

We are grateful to T. Pincus, P. O'Donnell, and A. Axelrad for communicating their results before publication. We thank Nancy Hopkins for stimulating discussions and Anne Cotellesa for her excellent technical assistance.

This work was supported by grant VC-4F from the American Cancer Society and Public Health Service grant CA14051 from the National Cancer Institute. P.J. is a Fellow of the Medical Research Council of Canada. D.B. is a Research Professor of the American Cancer Society.

\section{LITERATURE CITED}

1. Aaronson, S. A., and G. J. Todaro. 1968. Development of 3T3-like lines from BALB/c mouse embryo cultures: transformation susceptibility to SV-40. J. Cell. Physiol. 72:141-148.

2. Declève, A., O. Niwa, E. Gelmann, and H. S. Kaplan. 1975. Kinetics of propagation of B-tropic murine leukemia virus on $\mathrm{Fv-1}{ }^{\mathrm{b}}$ cell lines: requirement for multiple cycles of cell replication for transformation and viral antigen expression by RadLV. Virology 63:367383.

3. Declève, A., O. Niwa, E. Gelmann, and H. S. Kaplan. 1975. Replication kinetics of $\mathrm{N}$ - and B-tropic murine leukemia viruses on permissive and non-permissive cells in vitro. Virology 65:320-332.

4. Gisselbrecht, S., R. H. Bassin, B. I. Gerwin, and A. Rein. 1974. Dual susceptibility of a 3T3 mouse cell line to infection by $\mathrm{N}$ - and $\mathrm{B}$ - tropic murine leukemia virus: apparent lack of expression of the Fv-1 gene. Int. J. Cancer 14:106-113.

5. Hartley, J. W., W. P. Rowe, W. I. Capps, and R. J. Huebner. 1969. Isolation of naturally occurring viruses of the murine leukemia virus group in tissue culture. J. Virol. 3:126-132.

6. Hartley, J. W., W. P. Rowe, and R. J. Huebner. 1970. Host range restrictions of murine leukemia viruses in mouse embryo cell cultures. J. Virol. 5:221-225.

7. Huang, A. S., P. Besmer, L. Chu, and D. Baltimore. 1973. Growth of pseudotypes of vesicular stomatitis virus with $\mathrm{N}$-tropic murine luekemia virus coats in cells resistant to $\mathrm{N}$-tropic viruses. J. Virol. 12:659662.

8. Jainchill, J. L., S. A. Aaronson, and G. J. Todaro. 1969. Murine sarcoma and leukemia viruses: assay using clonal lines of contact-inhibited mouse cells. J. Virol. 4:549-553.

9. Krontiris, T. G., R. Soeiro, and B. N. Fields. 1973. Host restriction of Friend leukemia virus. Role of the viral outer coat. Proc. Natl. Acad. Sci. U.S.A. 70:25492553.

10. Lilly, F., and T. Pincus. 1973. Genetic control of murine viral leukemogenesis. Adv. Cancer Res. 17:231-277.

11. Pincus, T., J. W. Hartley, and W. P. Rowe. 1971. A major genetic locus affecting resistance to infection with murine leukemia viruses. I. Tissue culture studies of naturally occurring viruses. J. Exp. Med. 133:1219-1233.

12. Pincus, T., J. W. Hartley, and W. P. Rowe. 1975. A major genetic locus affecting resistance to infection with murine leukemia viruses. IV. Dose-response relationships in Fv-1 sensitive and resistant cell cultures. Virology 65:333-342.

13. Pincus, T., W. P. Rowe, and F. Lilly. 1971. A major genetic locus affecting resistance to infection with murine leukemia viruses. II. Apparent identity to a major locus described for resistance to Friend murine leukemia virus. J. Exp. Med. 133:1234-1241.

14. Rowe, W. P., W. E. Pugh, and J. W. Hartley. 1970. Plaque assay techniques for murine leukemia viruses. Virology 42:1136-1139.

15. Stephenson, J. R., R. K. Reynolds, and S. A. Aaronson. 1972. Isolation of temperature sensitive mutants of murine leukemia virus. Virology 48:749-756.

16. Tennant, R. W., F. E. Myer, and L. McGrath. 1974. Effect of the Fv-1 gene on leukemia virus in mouse cell heterokaryons. Int. J. Cancer 14:504-513.

17. Ware, L. M., and A. A. Axelrad. 1972. Inherited resistance to $\mathrm{N}$ - and $\mathrm{B}$-tropic murine leukemia viruses in vitro: evidence that congenic mouse strains SIM and SIM.R differ at the Fv-1 locus. Virology 50:339-348.

18. Yoshikura, H. 1973. Ultraviolet inactivation of murine leukemia virus and its assay in permissive and nonpermissive cells. Int. J. Cancer 11:739-746. 